\title{
Development of microsatellite loci for two New World vultures (Cathartidae)
}

\author{
Darren J. Wostenberg ${ }^{1}$, Jennifer A. Fike ${ }^{2}$, Sara J. Oyler-McCance ${ }^{2}$, Michael L. Avery ${ }^{3}$ and Antoinette J. Piaggio ${ }^{1^{*}}$ (D)
}

\begin{abstract}
Objective: Use next-generation sequencing to develop microsatellite loci that will provide the variability necessary for studies of genetic diversity and population connectivity of two New World vulture species.

Results: We characterized 11 microsatellite loci for black vultures (Coragyps atratus) and 14 loci for turkey vultures (Cathartes aura). These microsatellite loci were grouped into 3 multiplex panels for each species. The number of alleles among black vulture samples ranged from 2 to 11 , and 3 to 48 among turkey vulture samples.
\end{abstract}

Keywords: Black vulture, Turkey vulture, Microsatellites, Next-generation sequencing, Genetic diversity

\section{Introduction}

New World vultures (Cathartidae) are a monophyletic group that diverged from other bird species 55 million years ago [1]. This group of scavenging-specialized birds provide critical ecosystem services [2], and one genus of this family is critically endangered, California Condor (Gymnogyps). Data from the US Breeding Bird Survey indicate that during 2005-2015, turkey vulture (Cathartes aura) populations grew by $3.1 \%$ annually and black vultures (Coragyps atratus) increased 5.9\% annually during the same period [3]. These two species are well adapted to human-dominated landscapes $[2,4]$ and coincident with rising populations have been reports of increased property damage, livestock depredations, and aircraft safety issues associated with vultures [4-6].

Throughout most of their range, black vultures are resident year-round, but they do make irregular short-term movements in response to adverse weather conditions [4]. Turkey vultures are highly migratory with large numbers of wintering birds enlarging local populations in the southern US from late fall to early spring [4]. Both species have expanded their ranges northward over the past 50 years [4]. Using molecular methods to further investigate the ecological characteristics of these species could

\footnotetext{
*Correspondence: Toni.J.Piaggio@usda.gov

1 USDA APHIS, National Wildlife Research Center, 4101 Laporte Ave, Fort Collins, CO 80521, USA

Full list of author information is available at the end of the article
}

help inform our understanding of the roles these birds play in their present and expanded range. The high mutation rate and heritability of microsatellites make them ideal markers for studying demographic patterns [7].

Microsatellite loci have been developed for several Old World vulture species [8-11], yet only one New World vulture species, the critically endangered California condor (Gymnogyps californianus) [12]. Therefore, our goal was to use next-generation sequencing to develop microsatellite panels for two broad-ranging, genetically-diverse species of New World vultures, turkey vultures and black vultures. Development of species-specific markers reduces the risk of ascertainment bias that can occur when applying markers developed in other species [13]. These markers could be used to reliably assess genetic diversity, population connectivity, relatedness among individuals, demographic parameters, and population boundaries for black and turkey vultures. In concert with ecological field studies such as satellite telemetry studies, this information can be used to better understand the ecology of black and turkey vultures across their ranges.

\section{Main text \\ Methods}

Tissue samples (muscle) for microsatellite primer development were collected from black vultures and turkey vultures from control efforts in Alachua County, Florida in April 2004 and February 2011, respectively. Control 
efforts were performed on military bases and conducted by the USDA, Wildlife Services, National Wildlife Research Center personnel to reduce collisions between vultures and military aircraft. DNA for shotgun genome sequencing and primer development was isolated from one tissue sample from each species using a modified ammonium acetate protocol (Gentra Puregene Kit QIAGEN, Hilden, Germany). Shotgun sequencing libraries were developed using a Nextera DNA Sample Preparation Kit (Illumina, San Diego, California, USA) following the manufacturer's instructions. Libraries were pooled and sequenced in one 300 bp PE MiSeq v.3 (Illumina) run. The Perl script PAL_FINDER_v0.02.03 [14], which uses Primer3 [15] for primer design, was used to identify and design primers for potential microsatellite loci. The MiSeq run FASTA files were submitted to GenBank (SRA accession: PRJNA498072).

Samples used to evaluate amplification and heterozygosity of selected primer pairs were obtained from single populations of black vultures $(n=30)$ and turkey vultures $(n=30)$. Black vulture blood samples were collected at Everglades National Park, Florida in November and December 2012. Turkey vulture blood samples were collected at Key West Naval Air Station, Florida in January and February 2013. DNA was isolated from the blood samples using the DNeasy Blood \& Tissue Kit and QIAcube robotic workstations (QIAGEN). M13 primer sequences were added to the $5^{\prime}$ end of the forward primer in each primer pair. PCRs were performed in a $9-\mu \mathrm{L}$ reaction using $1.0 \mu \mathrm{L}$ of template DNA, $0.2 \mu \mathrm{L} \mathrm{GoTaq}^{\circledR}$ Flexi DNA polymerase (Promega, Madison, Wisconsin, USA), $2.0 \mu \mathrm{L} 5 \times$ buffer (Promega), $1.0 \mu \mathrm{L}$ dNTP (Promega), $1.0 \mu \mathrm{L} \mathrm{MgCl}_{2} 25 \mathrm{mM}$ (Promega), $1.0 \mu \mathrm{L}$ of each $10 \mu \mathrm{M}$ primer, and $1.0 \mu \mathrm{L}$ of $1 \mu \mathrm{M}$ M13 primer labeled with 6-FAM. All reactions were amplified on a Mastercycler ep Gradient thermal cycler (Eppendorf, Hamburg, Germany) using the thermal profile initial denaturation at $94{ }^{\circ} \mathrm{C}$ for $5 \mathrm{~min}$ followed by 35 cycles of $94{ }^{\circ} \mathrm{C}$ for $30 \mathrm{~s}$, $58{ }^{\circ} \mathrm{C}$ for $45 \mathrm{~s}$, and $72{ }^{\circ} \mathrm{C}$ for $45 \mathrm{~s}$. Cycling was followed with a final extension for $5 \mathrm{~min}$ at $60{ }^{\circ} \mathrm{C}$. PCR products were added to a mixture of HiDi Formamide (Life Technologies, Carlsbad, California, USA) and GeneScan 500 LIZ Size Standard (Life Technologies). Samples were run on an ABI 3500 genetic analyzer (Life Technologies) and loci performance was manually evaluated using GeneMapper v.5.0 (Life Technologies).

Loci were organized into three panels based on PCR product size range and primer complementarity using Multiplex Manager v.1.2 [16] for each species (Tables 1, 2 , 3). Forward primers were ordered from Applied Biosystems (Life Technologies) with the $5^{\prime}$ fluorescent dyes 6-FAM, VIC, NED, and PET and PIG-tails [17] added to the $5^{\prime}$ end of the reverse primer to reduce stutter
(Tables 1, 2). PCR chemistry and primer volumes were optimized for each panel using QIAGEN $2 \times$ Multiplex PCR Master Mix and 1.0 $\mu \mathrm{L}$ of template DNA. All reactions were amplified on an Eppendorf Mastercycler thermal cycler using the thermal profile: initial denaturation at $94{ }^{\circ} \mathrm{C}$ for 5 min followed by panel-specific number of cycles (Table 3) of $94{ }^{\circ} \mathrm{C}$ for $30 \mathrm{~s}, 58^{\circ} \mathrm{C}$ for $45 \mathrm{~s}$, and $72{ }^{\circ} \mathrm{C}$ for $45 \mathrm{~s}$. Cycling was followed with a final extension for $5 \mathrm{~min}$ at $60{ }^{\circ} \mathrm{C}$. Samples were genotyped as described above.

Loci were tested for Hardy-Weinberg equilibrium (HWE) and linkage disequilibrium with observed and expected heterozygosity calculated using Arlequin v.3.5 [18]. Microsatellite loci were checked for the presence of null alleles using Micro-Checker v.2.2.3 [19].

Microsatellite loci designed for each species were tested for PCR amplification in the opposite vulture species (BLVU markers with turkey vulture DNA samples and TUVU markers with black vulture DNA samples). Ten samples were used to test for amplification in each species. Cross-species PCR amplification was performed at the optimized PCR conditions for the target species.

\section{Results}

The MiSeq run generated 9,772,498 $(2 \times 4,886,249)$ reads for black vultures and PAL_FINDER identified 59,440 reads with microsatellites. Primer pairs were selected randomly and targeted di-nucleotide, tri-nucleotide, and tetra-nucleotide repeats with minimal complexity in the repeat regions. Based on cost limitations, 58 black vulture microsatellite loci were tested for amplification and polymorphism. Of these 11 loci were identified as polymorphic and amplified consistently. For these 11 loci, the number of alleles ranged from 2 to 11, observed heterozygosity ranged from 0.06 to 0.74 , and the expected heterozygosity ranged from 0.06 to 0.84 (Table 1 ). After Bonferroni corrections [20], three loci showed significant deviation from HWE (BLVU-05, BLVU-11, and BLVU38) and no loci showed significant evidence of linkage. Estimates of heterozygote deficiency used to detect the presence of null alleles in microsatellite data [19, 21, 22] indicated the presence of null alleles in the black vulture loci BLVU-05, BLVU-11, and BLVU-38.

The MiSeq run generated 9,248,148 $(2 \times 4,624,074)$ reads for turkey vultures and PAL_FINDER identified 60,353 reads with microsatellites. Primer pairs for 59 turkey vulture microsatellite loci were tested for amplification and polymorphism. Of these 14 loci were identified as polymorphic and amplified consistently. For these 14 loci, the number of alleles ranged from 3 to 47, observed heterozygosity ranged from 0.07 to 1.00 , and the expected heterozygosity ranged from 0.39 to 0.99 (Table 2). After Bonferroni corrections [20], 2 loci showed significant 
Table 1 Primer sequences, motifs, and characteristics of the 11 microsatellite loci developed and optimized from the black vulture (Coragyps atratus)

\begin{tabular}{|c|c|c|c|c|c|c|c|c|c|}
\hline Locus & Panel & Dye label & $\begin{array}{l}\text { Primer sequence }\left(5^{\prime}-3^{\prime}\right) ; F \text {, } \\
\text { forward; } R \text {, reverse }\end{array}$ & Repeat motif & $n$ & Size range (bp) & $N_{\mathrm{A}}$ & $H_{\mathrm{O}}$ & $H_{\mathrm{E}}$ \\
\hline \multirow[t]{2}{*}{ BLVU-36 } & A & 6-FAM & F: CTGAACGGAAACAGAGCTGC & $\mathrm{AAAG}_{(7)} \mathrm{AACG}_{(6)}$ & 30 & $223-242$ & 4 & 0.68 & 0.66 \\
\hline & & & R: CACTATGACCCCTTATGACTCTGG & & & & & & \\
\hline \multirow[t]{2}{*}{ BLVU-1 $1^{a, b}$} & A & $\mathrm{VIC}$ & F: CTTGAAGAGCAAAGTCGGGG & $\mathrm{AGT}_{(13)} \mathrm{TTC}_{(11)}$ & 30 & $225-237$ & 3 & 0.10 & 0.42 \\
\hline & & & R: AGGACAAATGTGCCTTTCGG & & & & & & \\
\hline \multirow[t]{2}{*}{ BLVU-37 } & A & PET & F: CTAATGGCTCCAGACCCAGG & $\operatorname{TATC}_{(12)}$ & 30 & $258-266$ & 3 & 0.52 & 0.46 \\
\hline & & & R:TTTTGTCCACCTCCTGTCCC & & & & & & \\
\hline \multirow[t]{2}{*}{ BLVU-05 $5^{a, b}$} & B & 6-FAM & F: GACCTATCCACATGAATGCC & $\mathrm{GA}_{(37)} \mathrm{AG}_{(17)}$ & 30 & $295-317$ & 9 & 0.32 & 0.64 \\
\hline & & & R: GCCTCTGTTAGTATTCCATCCCC & & & & & & \\
\hline \multirow[t]{2}{*}{ BLVU-38 } & B & 6-FAM & F:TGTCACCTGGAGCTCTGTCC & $\operatorname{ATCT}_{(13)}$ & 30 & $168-188$ & 5 & 0.29 & 0.62 \\
\hline & & & R:TCATTAGCATGAAATGAAGGTGC & & & & & & \\
\hline \multirow[t]{2}{*}{ BLVU-09 } & B & $\mathrm{VIC}$ & F: CCTCCATAGATGTGCCCTAACC & $\mathrm{GAAA}_{(12)} \mathrm{AAGG}_{(18)}$ & 30 & $272-320$ & 5 & 0.39 & 0.39 \\
\hline & & & R: ACAGCTTCTCCCTGTGTCCC & & & & & & \\
\hline \multirow[t]{2}{*}{ BLVU-18 } & B & PET & F: CTCTCTCTAACCGGCTCTACGC & $\mathrm{GTT}_{(10)}$ & 30 & $117-123$ & 2 & 0.06 & 0.06 \\
\hline & & & R: GAAGAAGAGAGAGGCGGCG & & & & & & \\
\hline \multirow[t]{2}{*}{ BLVU-33 } & C & 6-FAM & F: GGGTAGCAAGAGAAAGAGGGG & $\mathrm{AGAC}_{(6)} \mathrm{GGAA}_{(7)}$ & 30 & $350-406$ & 11 & 0.71 & 0.84 \\
\hline & & & R: ATTGTGCATTTCCTCCTGGC & & & & & & \\
\hline \multirow[t]{2}{*}{ BLVU-39 } & C & $\mathrm{VIC}$ & F: CTTCCTTCCTCTGCCTGC & $\operatorname{TGCC}_{(14)}$ & 30 & 109-129 & 5 & 0.74 & 0.70 \\
\hline & & & R:TGAACAGGACTTGATTGTCTCC & & & & & & \\
\hline \multirow[t]{2}{*}{ BLVU-40 } & C & NED & F: CCTCTATTGGCTTCAGCAGG & $\operatorname{TTCC}_{(8)}$ & 30 & $274-282$ & 3 & 0.45 & 0.50 \\
\hline & & & R: GCAAGAGGAAGAGTGGAAGG & & & & & & \\
\hline \multirow[t]{2}{*}{ BLVU-27 } & C & PET & F: CCAAAACCTGCCACTGTCC & AAAT $_{(12)}$ & 30 & $214-226$ & 3 & 0.65 & 0.59 \\
\hline & & & R: GGTGACATTTTAATGCTGGGC & & & & & & \\
\hline
\end{tabular}

$n$ is the sample size, $N_{\mathrm{A}}$ is the number of alleles, $H_{\mathrm{O}}$ is the observed heterozygosity, and $H_{\mathrm{E}}$ is the expected heterozygosity

a Showed significant deviation from Hardy-Weinberg equilibrium after Bonferroni corrections [20]

b Showed evidence of null alleles

deviation from HWE (TUVU-14 and TUVU-36) and no loci showed significant evidence of linkage. Null alleles were detected in the turkey vulture loci TUVU-14, TUVU-21, TUVU-36, and TUVU-39.

The majority of loci for each species amplified when tested using template DNA from the opposite species under optimized PCR conditions. Eight of 11 (72.7\%) BLVU loci amplified using turkey vulture DNA samples, and 10 of 14 (71.4\%) TUVU loci amplified using black vulture DNA samples (Additional file 1: Tables S1, S2). Five loci reliably amplified in both species $(n=10$ of each species) and produced unique allelic distributions for each species and could thus be used to separate the species and identify each uniquely in a single multiplexed PCR panel (Additional file 1: Table S3).

\section{Discussion}

The development of these microsatellite loci provides a new tool for studying New World vulture populations. Data generated from these markers could help better understand vulture demography, population structure, and relationships among individuals at a roost site. While both sets of microsatellite loci were variable for the samples tested, the TUVU loci included multiple hypervariable loci (loci with $\geq 20$ alleles: TUVU-39, 20 alleles; TUVU-03, 30 alleles; TUVU-37, 34 alleles; and TUVU01, 47 alleles; Table 2). Not considering these four markers, the remaining 10 TUVU loci averaged 7.9 alleles per marker. The BLVU loci averaged 4.8 alleles across 11 markers.

The evaluation of amplification of markers developed in one species in the other species (e.g. black vulture markers tested in turkey vultures) revealed that at least half of each set of loci generate PCR products in the other species at the optimized PCR conditions, however only a few loci from each group performed particularly well. Among the BLVU loci, BLVU-09, BLVU-18, BLVU-27, BLVU-33, BLVU-36, and BLVU-39 generated clear polymorphic chromatograms with distinct alleles and could be used in addition to the turkey vulture microsatellite panels. Among the TUVU loci, TUVU-18, TUVU-21, TUVU-31, TUVU-33, and TUVU-45 generated clear polymorphic chromatograms with distinct alleles in black vultures. 
Table 2 Primer sequences, motifs, and characteristics of the 14 microsatellite loci developed and optimized from the turkey vulture (Cathartes aura)

\begin{tabular}{|c|c|c|c|c|c|c|c|c|c|}
\hline Locus & Panel & Dye label & Primer sequence $\left(5^{\prime}-3^{\prime}\right) ; F$, forward; $R$, reverse & Repeat motif & $n$ & $\begin{array}{l}\text { Allele size } \\
\text { range (bp) }\end{array}$ & $N_{\mathrm{A}}$ & $H_{\mathrm{O}}$ & $H_{\mathrm{E}}$ \\
\hline TUVU-21 ${ }^{\mathrm{b}}$ & A & 6-FAM & $\begin{array}{l}\text { F: TTGTTTGGCTCCATGTTTGG } \\
\text { R: ACACCCATTCAAATGCAAGC }\end{array}$ & $\mathrm{CT}_{(10)} A \mathrm{C}_{(8)} \mathrm{AC}_{(10)}$ & 30 & $202-210$ & 3 & 0.20 & 0.39 \\
\hline TUVU-06 & A & 6-FAM & $\begin{array}{l}\text { F: GAGTCAGCAATGGTGGTTGC } \\
\text { R: ACTGTAGCAGTGACGGCAGC }\end{array}$ & $\mathrm{GAA}_{(25)} \mathrm{GAA}_{(8)}$ & 30 & $326-533$ & 17 & 0.77 & 0.83 \\
\hline TUVU-31 & A & $\mathrm{VIC}$ & $\begin{array}{l}\text { F: AAGTAAATAGCTGTCTAACTGTTCATCC } \\
\text { R: CTTTCATGCCTTGATTTCCC }\end{array}$ & $\mathrm{TG}_{(15)} A \mathrm{~T}_{(8)}$ & 30 & $122-152$ & 8 & 0.73 & 0.81 \\
\hline TUVU-23 & A & NED & $\begin{array}{l}\text { F: GAAACGGTATTTGCCTTGCC } \\
\text { R: AAAACTCCAAGGGGAGGAGG }\end{array}$ & $\operatorname{TTCC}_{(12)}$ & 30 & $155-161$ & 6 & 0.60 & 0.60 \\
\hline TUVU-39 & A & PET & $\begin{array}{l}\text { F: GGTTCAGGTGAGAGAAACCCC } \\
\text { R: GAAAACCCCTCTGGGAAACC }\end{array}$ & $\operatorname{AAAG}_{(23)}$ & 30 & $188-311$ & 20 & 0.77 & 0.90 \\
\hline TUVU-14 & B & 6-FAM & $\begin{array}{l}\text { F: CCTAGTCCGGAAACACAGGG } \\
\text { R:TTAAACTGAAATGTGTGAAGAAGCG }\end{array}$ & $\operatorname{ATT}_{(14)} \operatorname{ATT}_{(6)}$ & 30 & $347-371$ & 7 & 0.50 & 0.75 \\
\hline TUVU-07 & B & 6-FAM & $\begin{array}{l}\text { F: TGGGATGTGAAGGAGAACAGC } \\
\text { R:TGACTCCTGTACAAAATTAGATCCTTCC }\end{array}$ & $\mathrm{GGAA}_{(28)}$ & 30 & $160-226$ & 15 & 0.87 & 0.92 \\
\hline TUVU-45 & B & $\mathrm{VIC}$ & $\begin{array}{l}\text { F: AATAATCCATGAGCACCAGGC } \\
\text { R: CCCATAAACTCAAGCATTGGC }\end{array}$ & $\mathrm{GTTT}_{(14)}$ & 30 & $131-158$ & 7 & 0.50 & 0.45 \\
\hline TUVU-03 & B & PET & $\begin{array}{l}\text { F: AGGTTCATTAGCAGAGGCGG } \\
\text { R: GTGGCAGAAAGAAGCTGAAGG }\end{array}$ & $\mathrm{AAAG}_{(9)} \mathrm{AAAG}_{(18)}$ & 30 & $261-375$ & 30 & 1.00 & 0.96 \\
\hline TUVU-01 & C & 6-FAM & $\begin{array}{l}\text { F: TCATACACTGGTCGTTCGCC } \\
\text { R: ATTGAAATGCCCTACAGACGG }\end{array}$ & $\mathrm{TC}_{(6)} \mathrm{CTTT}_{(24)} \mathrm{CTTT}_{(12)}$ & 30 & $290-640$ & 47 & 1.00 & 0.99 \\
\hline TUVU-18 & $C$ & $\mathrm{VIC}$ & $\begin{array}{l}\text { F: GGTTCTGCTGATTTCAACTTTGC } \\
\text { R: TTCACCACAGGAAACCAAAGC }\end{array}$ & $\operatorname{TAA}_{(11)} \mathrm{TGA}_{(9)}$ & 30 & $240-249$ & 4 & 0.50 & 0.47 \\
\hline TUVU-37 & C & NED & $\begin{array}{l}\text { F: GCTGGTTTTGAACAGTGAGGG } \\
\text { R:TTACAGGTGGGGAATCTCAGG }\end{array}$ & $\operatorname{AAAG}_{(27)} \mathrm{AAAG}_{(8)}$ & 30 & $263-415$ & 34 & 0.93 & 0.97 \\
\hline TUVU-33 & C & PET & $\begin{array}{l}\text { F: GCAAATCAGCCTCTGGTGG } \\
\text { R: TTAACTTGGAGGCCAGGAGG }\end{array}$ & $\mathrm{TA}_{(13)} \mathrm{TA}_{(6)}$ & 30 & $330-339$ & 9 & 0.77 & 0.83 \\
\hline TUVU-36 & C & PET & $\begin{array}{l}\text { F: CACACGCACACAATGCACC } \\
\text { R: CACTGCGCGAGTGTGAGG }\end{array}$ & $\mathrm{GC}_{(8)}$ & 30 & 169-173 & 3 & 0.07 & 0.45 \\
\hline
\end{tabular}

$n$ is the sample size, $N_{\mathrm{A}}$ is the number of alleles, $H_{\mathrm{O}}$ is the observed heterozygosity, and $H_{\mathrm{E}}$ is the expected heterozygosity

a Showed significant deviation from Hardy-Weinberg equilibrium after Bonferroni corrections [20]

b Showed evidence of null alleles

Table 3 Multiplex PCR characteristics for the three optimized black vulture (Coragyps atratus) microsatellite panels (BLVU) and the three optimized from the turkey vulture (Cathartes aura) microsatellite panels (TUVU)

\begin{tabular}{llllllll}
\hline Panel & $\begin{array}{l}\text { Reaction volume } \\
(\boldsymbol{\mu L})\end{array}$ & $\boldsymbol{T}_{\mathbf{a}}\left({ }^{\circ} \mathrm{C}\right)$ & No. of cycles & Panel & $\begin{array}{l}\text { Reaction volume } \\
(\boldsymbol{\mu L})\end{array}$ & $\boldsymbol{T}_{\mathbf{a}}\left({ }^{\circ} \mathrm{C}\right)$ & No. of cycles \\
\hline BLVU-A & 10.0 & 58 & 32 & TUVU-A & 13.0 & 58 & 34 \\
BLVU-B & 9.0 & 58 & 32 & TUVU-B & 16.0 & 58 & 37 \\
BLVU-C & 9.0 & 58 & 32 & TUVU-C & 15.0 & 58 & 44 \\
\hline
\end{tabular}

$T_{\mathrm{a}}$ is the annealing temperature and no. of cycles is the number of amplification cycles in the thermal cycler protocol

These microsatellite markers represent a robust subset of possible markers identified by our genome sequencing results. Financial limitations and planned studies for these markers resulted in the identified markers being sufficient for our purposes. However, for other researchers with time and resources to pursue other markers, we have provided a summary of our PAL FINDER results for each species (Additional files 2, 3). We have identified the primer combinations we tested and made comments regarding their performance. In 
the meantime, we have provided a set of markers that are polymorphic, perform reliably, and thus can be used for population genetics studies of these two New World vulture species.

\section{Limitations}

- Many of the black vulture loci have only a few alleles so more loci might be needed for some research questions.

- Microsatellites are neutral markers, so they are not useful when investigating adaptation/selection.

- We did not spend much time optimizing loci; we only used ones that worked in initial screenings. Therefore, we may have excluded loci that would work and be polymorphic with more effort.

\section{Additional files}

Additional file 1: Table S1. Summary of cross-species PCR amplification of black vulture (Coragyps atratus) microsatellite primers tested on turkey vulture (Cathartes aura) samples under optimized PCR conditions. Table heading abbreviations are $n$ is the sample size and $N_{A}$ is the number of alleles. Table S2. Summary of cross-species PCR amplification of turkey vulture (Cathartes aura) microsatellite primers tested on black vulture (Coragyps atratus) samples under optimized PCR conditions. Table heading abbreviations are $n$ is the sample size and $N_{A}$ is the number of alleles. Table S3. A potential panel of markers that can provide species identification between BLVU and TUVU. $N_{A}$ is the number of alleles and $T_{A}$ is the annealing temperature for the primer pair. Dye is the fluorophore for the marker pair to be visualized on an ABI3500 genetic analyzer.

Additional file 2. PAL_FINDER results for black vulture (Coragyps atratus) next-generation sequencing run on Illumina MiSeq. MiSeq run files were submitted to the National Center for Biotechnology Information Sequence Read Archive (accession number PRJNA498072).

Additional file 3. PAL_FINDER results for turkey vulture (Cathartes aura) next-generation sequencing run on Illumina MiSeq. MiSeq run files were submitted to the National Center for Biotechnology Information Sequence Read Archive (accession number PRJNA498072).

\section{Abbreviations}

PCR: polymerase chain reaction; bp: base pair; PE: paired end; BLVU: black vulture; TUVU: turkey vulture; HWE: Hardy-Weinberg equilibrium; $\mathrm{N}_{\mathrm{A}}$ : number of alleles; $\mathrm{H}_{\mathrm{O}}$ : observed heterozygosity; $\mathrm{H}_{\mathrm{E}}$ : expected heterozygosity; $\mathrm{T}_{\mathrm{a}}$ : annealing temperature.

\section{Acknowledgements}

The findings and conclusions in this preliminary publication have not been formally disseminated by the United States Department of Agriculture and should not be construed to represent any agency determination or policy. We express our deep gratitude to M. Rodriguez for technical assistance and G. Herring, J. Humphrey, E. Tillman, S. Snow, L. Oberfhofer, R. Gonzales, E. Stolen, R. Hinnah, and L. Pharr for collecting samples and/or organizing the collection from secure sites. Any use of trade, firm, or product names is for descriptive purposes only and does not imply endorsement by the U.S. Government.

\section{Authors' contributions}

DJW performed sample DNA extractions, fragment analysis and genotyping, and helped write the manuscript. JAF did the next-generation sequencing library prep, Miseq run, PAL_FINDER analysis and helped write the manuscript. SJOM, MLA, AJP conceived the study and helped write the manuscript. All authors read and approved the final manuscript.

\section{Funding}

This research was supported by the intramural research program of the United States Department of Agriculture, Animal and Plant Health Inspection Service, Wildlife Services (WS), National Wildlife Research Center (NWRC) methods development appropriated funds. These funds support the WS/NWRC mission and research scientists (Piaggio \& Avery) have discretion for designing studies, collecting data, analyses, and data interpretation in support of this mission.

\section{Availability of data and materials}

The MiSeq run FASTA files were submitted to GenBank (SRA accession: PRJNA498072). A summary of our PAL_FINDER results for each species can be found in Additional files 2, 3.

\section{Ethics approval and consent to participate}

Collection of animal tissues did not require private owner consent as they were not privately owned. All appropriate permits were obtained.

\section{Consent for publication}

Not applicable.

\section{Competing interests}

The authors declare that they have no competing interests.

\section{Author details}

${ }^{1}$ USDA APHIS, National Wild life Research Center, 4101 Laporte Ave, Fort Collins, CO 80521, USA. ${ }^{2}$ U.S. Geological Survey, Fort Collins Science Center, 2150 Centre Ave \#C, Fort Collins, CO 80526, USA. ${ }^{3}$ USDA APHIS, National Wildlife Research Center, Florida Field Station, 2820 E University Ave, Gainesville, FL 32641, USA.

Received: 18 March 2019 Accepted: 3 May 2019

Published online: 09 May 2019

\section{References}

1. Prum RO, Berv JS, Dornburg A, Field DJ, Townsend JP, Lemmon EM, et al. A comprehensive phylogeny of birds (Aves) using targeted next-generation DNA sequencing. Nature. 2015;526(7574):569-73D.

2. Devault TL, Beasley JC, Olson ZH, Moleón M, Carrete M, Margalida A, Sánchez-Zapata JA. Ecosystem services provided by avian scavengers. In: Şekercioğlu CH, Wenny DG, Whelan CJ, editors. Why Birds Matter: Avian Ecological Function and Ecosystem Services. Chicago: University of Chicago Press; 2016.

3. Sauer JR, Niven DK, Hines JE, Ziolkowski DJ Jr, Pardieck KL, Fallon JE, et al. The North American breeding bird survey, results and analysis 1966-2015. Version 2.07.2017. In: USDI, Geological Survey, Patuxent Wildlife Research Center, editor. Laurel; 2017.

4. Avery ML, Lowney MS. Vultures. In: USDA, Animal and Plant Health Inspection Service, Wildlife Services, National Wildlife Research Center, editor. Fort Collins; 2016. p. 1-17.

5. Lowney MS. Damage by black and turkey vultures in Virginia, 1990-1996. Wildl Soc Bull. 1999;27(3):715-9.

6. Avery ML, Humphrey JS, Daughtery TS, Fischer JW, Milleson MP, Tillman EA, et al. Vulture flight behavior and implications for aircraft safety. J Wildl Manag. 2011;75(7):1581-7.

7. Selkoe KA, Toonen RJ. Microsatellites for ecologists: a practical guide to using and evaluating microsatellite markers. Ecol Lett. 2006;9(5):615-29.

8. Gautschi B, Tenzer I, Müller JP, Schmid B. Isolation and characterization of microsatellite loci in the bearded vulture (Gypaetus barbatus) and cross-amplification in three Old World vulture species. Mol Ecol. 2000;9(12):2193-5. 
9. Agudo R, Roques S, Galarza JA, Rico C, Hiraldo F, Donázar JA. Isolation and characterization of 18 microsatellite loci in the Egyptian vulture (Neophron percnopterus). Conserv Genet. 2008;9(5):1345-8.

10. Mira S, Billot C, Guillemaud T, Palma L, Cancela M. Isolation and characterization of polymorphic microsatellite markers in Eurasian vulture Gyps fulvus. Mol Ecol Resour. 2002;2(4):557-8.

11. Kapetanakos Y, Lovette I, Katzner T. Development of microsatellite markers and a restriction endonuclease digest assay for non-invasive sampling of endangered White-rumped, Slender-billed and Red-headed vultures. Conserv Genet Resour. 2014;6(3):539-42.

12. Romanov MN, Tuttle EM, Houck ML, Modi WS, Chemnick LG, Korody ML, et al. The value of avian genomics to the conservation of wildlife. BMC Genomics. 2009;10(2):S10.

13. Ellegren H, Moore S, Robinson N, Byrne K, Ward W, Sheldon BC. Microsatellite evolution - a reciprocal study of repeat lengths at homologous loci in cattle and sheep. Mol Biol Evol. 1997;14(8):854-60.

14. Castoe TA, Poole AW, de Koning AJ, Jones KL, Tomback DF, OylerMcCance SJ, et al. Rapid microsatellite identification from Illumina paired-end genomic sequencing in two birds and a snake. PLOS ONE. 2012:7(2):e30953.

15. Rozen S, Skaletsky H. Primer3 on the WWW for general users and for biologist programmers. In: Krawetz S, Misener S, editors. Bioinformatics methods and protocols: methods in molecular biology. New Jersey; Humana Press; 2000. p. 365-86.
16. Holleley CE, Geerts PG. Multiplex Manager 1.0: a cross-platform computer program that plans and optimizes multiplex PCR. Biotechniques. 2009;46(7):511-7.

17. Brownstein MJ, Carpten JD, Smith JR. Modulation of non-templated nucleotide addition by DNA polymerase: primer modifications that facilitate genotyping. BioTechniques. 1996;20(6):1004-10.

18. Excoffier $L$, Lischer HE. Arlequin suite version 3.5: a new series of programs to perform population genetics analyses under Linux and Windows. Mol Ecol Resour. 2010;10(3):564-7.

19. Van Oosterhout C, Hutchinson WF, Wills DP, Shipley P. Micro-Checker: software for identifying and correcting genotyping errors in microsatellite data. Mol Ecol Resour. 2004;4(3):535-8.

20. Rice WR. Analyzing tables of statistical tests. Evolution. 1989;43(1):223-5.

21. Brookfield J. A simple new method for estimating null allele frequency from heterozygote deficiency. Mol Ecol. 1996;5(3):453-5.

22. Chakraborty R, Andrade MD, Daiger S, Budowle B. Apparent heterozygote deficiencies observed in DNA typing data and their implications in forensic applications. Ann Hum Genet. 1992;56(1):45-57.

\section{Publisher's Note}

Springer Nature remains neutral with regard to jurisdictional claims in published maps and institutional affiliations.
Ready to submit your research? Choose BMC and benefit from:

- fast, convenient online submission

- thorough peer review by experienced researchers in your field

- rapid publication on acceptance

- support for research data, including large and complex data types

- gold Open Access which fosters wider collaboration and increased citations

- maximum visibility for your research: over $100 \mathrm{M}$ website views per year

At BMC, research is always in progress.

Learn more biomedcentral.com/submissions 